New Zealand Joumal of Industrial Relations, 1981, 6 121-124

\title{
Industrial Relations in smaller Countries: Introduction
}

This issue of the Journal introduces the first of what the editors hope will be a regular series of symposia on industrial relations topics of special relevance to our predominantly New Zealand readers, but also to those abroad.

The first topic "Industrial relations in smaller countries" was chosen because the editors hoped that it would allow a comparison of how some smaller countries have developed their industrial relations systems to cope with the problems that small size creates.

The four countries represented: Austria, Norway, Switzerland and the Republic of Ireland are all apparently similar to New Zealand in certain obvious aspects. These include their small populations, a high percentage of G.D.P. involved in foreign trade and the fact that they all are developed, western, democratic societies with a high standard of living.

Some statistical information on all four countries and New Zealand can be found in the appendix.

Whilst all four countries have much in common there are major differences, particularly historical, cultural and social differences. This has obvious implications for the development of unique industrial relations systems within each country and the variety of solutions put forward to deal with their common problems. Some problems differ, for example the large numbers of temporary immigrant workers in Austria and Switzerland create difficulties not facing other countries to any great degree. New Zealand has of course had some experience of an immigrant workforce and its attendant problems, particularly those that arise when economic downturns make it politically desirable to dispense with surplus labour.

The editors hope that the four invited contributors to the symposium will, in addition to introducing aspects of the industrial relations of each country, allow the reader to identify some common problems and methods by which these problems have been tackled. While the countries chosen have very different heritages they do share one feature, their small physical size. Whilst not providing universal panaceas it is hoped that the symposium will give some insight into how some smaller countries deal with industrial relations.

\section{External Pressures}

In a world dominated by a few superpowers size can lead to special problems for the smaller and less influential countries which affect all spheres of economic and cultural life. Many of the difficulties of smaller countries arise almost entirely from the dominant economic influence of larger countries. There are however also other influences. The legal systems and social and cultural life of a smaller country will often be heavily influenced by the radiation effect of a dominating larger neighbour. In the case of Norway and Austria one must also make mention of their wartime experience under German occupation.

The economies of smaller countries are normally very vulnerable to outside pressures since many depend upon a limited range of activities (such as primary products or a restricted level of manufacturing) and have limited capacity to withstand and absorb global economic pressures. Oil price rises, major changes in trading patterns or technological changes on a major scale can have a significant impact and internal pressures such as wage rises or changed working conditions may have repurcussions far beyond that to be expected in a larger country. 
One method of attempting to reduce the impact of economic pressures is by the creation of some form of incomes policy. Industrial relations between the parties in the countries represented in the symposium are all strongly influenced by an incomes policy of one sort or another, and by a significant government presence associated with the incomes policy. Incomes policies seem, in most cases, to have led to a high degree of tripartite cooperation. The failure of the parties in New Zealand to develop an agreed incomes policy is one of the major contrasts with the countries represented.

A workable incomes policy needs a high degree of co-operation and consensus between unions, employers and government. The political systems of the countries represented seem more able to produce this state of affairs than in New Zealand. The reasons for this are partly historical. In the case of Norway there has been a long history of co-operation, similarly in Austria, and to a lesser extent Switzerland. Pressures for co-operative activity generated by the period of Nazi domination of Europe have led to a measure of co-operation not found outside those countries which experienced German occupation. More importantly however, the nature of the political systems would seem to favour consensus and co-operative politics. European politics tend to be multi-party and dominated by coalitions, a situation which tends to favour consensus decision-making. In addition, socialist parties have had a major long-term influence in several of the countries surveyed.

These conditions contrast markedly with the New Zealand system of polarised twoparty politics, and the predominance in power of a government that tends to be hostile to unions in both attitudes and action.

The radiation effect of dominant countries often affects smaller countries indirectly in that they adopt the intellectual and policy models provided by the larger country. Thus both Ireland and New Zealand, as former British colonies, have adopted and been influenced by the British legal system. In New Zealand the Industrial Conciliation and Arbitration Act 1894 pre-empted much of the British trade union legislation which was applied to Ireland, but both Ireland and New Zealand share British common law heritages, including the law governing contracts of employment and the law of tort. Industrial torts and the possibility of injunctions and damages that arise from them would seem to be a thorn in the side of unionists in both countries. Both countries are also still strongly influenced by development of the law in the British courts. This highly political area of the law applies regardless of the fact that British social conditions may lead to decisions which are inappropriate or impractical in a foreign context.

This type of influence is not as apparent in the other countries discussed, although Norway in particular shares many features of its industrial relations system with its Scandinavian neighbours. Austria and Switzerland are less prone to foreign influence. Switzerland because of its traditional independence and Austria because of the special history of the present Austrian state, in particular its emergence from the ruins of the AustroHungarian Empire after World War I and later trauma of Nazism and post-war reconstruction.

\section{Internal Effects}

Smallness of size may of course be instrumental in leading to a co-operative climate. All the countries represented have developed stable political and economic systems characterised by a close degree of co-operation. This co-operative working relationship is also found among the decision-makers in the unions, the employers and the government, and is probably attributable in part to working together in joint institutions and because of a reasonably close ideological relationship. This latter cause seems particularly significant in the European countries. There are however signs that the consensus leadership of the post-war era is showing signs of strain and that the emergence of new leaders and the increase in economic pressures will see a greater degree of conflict develop (e.g. Brigouleix and Boyer, 1981). 
Another feature of the countries surveyed is that they all have reasonably well developed systems of social welfare and worker protection, although Switzerland seems to lag a little in this respect. Ireland, although late to develop in these areas, has made major advances in recent years especially since joining the European Community. Social welfare and worker protection are two areas where smaller countries have provided a model for the larger. These areas have been both pioneered and developed in countries such as New Zealand and those of Scandinavia. These developments may indicate a greater degree of social concern in the political systems of smaller countries.

The development of comprehensive welfare and protective systems has obvious implications for industrial relations and the role of the trade unions. The most important is that many issues of concern to workers such as pensions, accident compensation and minimum working conditions are removed from the industrial to the political arena. As a consequence the unions, if they are to influence these areas of policy, must develop political skills and, to some extent at least, become integrated into governmental and legislative processes. The development of incomes policies must advance this trend as welfare benefits and fiscal matters are as much a part of an incomes policy as wages.

The need for both a strong political, as well as industrial expertise, must place financial and human pressures on the parties to the industrial relations system. The unions especially have to compete with the greater financial resources of both government and business for the relatively small pool of expertise available in a smaller country. To some extent ideological commitment may replace the financial rewards of business for union employees.

\section{Problems of Comparison}

In industrial relations there is always a temptation to compare one's own system with some other system, usually in a search for solutions to problems which seem intractable. Press reports of returning employers lauding the German union structure, the Swedish strike statistics or the no-strike agreements in the United States are common. Similarly unions eye enviously the 'new technology' agreement of Norway and attempt to implement similar measures.

Comparative studies have both benefits and dangers. The benefits are that they introduce new ideas, challenge our own pre-conceived ideologies and attitudes to industrial problems and possibly give hints of solutions. The chief danger is that when some aspect of another country's system is isolated from its social, political and cultural context it may run the risk of losing its validity, and its rationale. The attempt to transplant United States labour law into the United Kingdom in the Industrial Relations Act 1971 is a classic illustration of how a misunderstanding of the limitations of comparative study can lead to poor legislation.

For comparative studies to have real value those writing or reading them must be able to overcome their own pre-conceptions and be able to understand not only the broad pattern, but also the detail, of the system under examination. A failure to appreciate differences of meaning in the same terminology may easily lead to mistaken assumptions. Schregle $(1981$, pp. 19-20) points out that the use of the term "labour court" means something very different from one country to another. Jurisdiction can vary widely and some 'courts', such as the Irish Labour Court, are not really courts at all. Hepple and Brown (1981, p.66) suggest that a researcher can only really hope to understand two or three systems in depth.

Comparative studies in industrial relations, if treated with caution and with a knowledge of both their and the reader's limitations, can provide valuable insights into other systems. Hopefully they may also generate ideas to solve one's own problems.

As Eldridge (1975) points out however, universal panaceas are "unworkable fantasies". 


\section{4}

\section{Introduction}

\section{Acknowledgement}

The editors wish to acknowledge the financial support of the Industrial Relations Foundation of New Zealand towards the costs associated with the production of this symposium.

Gordon Anderson Symposium Editor

\section{References}

Brigouleix, B. and M. Boyer (1981) Austrian socialism - a model strictly not for export. The Guardian Weekly October 11, p.14.

Eldridge, J.E.T. (1975) Panaceas and Pragmatism in Industrial Relations Industrial relations journal $6(1): 4-12$.

Hepple, B.A. and W.A. Brown (1981) Tasks for labour law research Legal Studies 1(1): 56-67.

Schregle, J. (1981) Comparative industrial relations: pitfalls and potential. International labour review $120(1): 15-30$.

APPENDRX

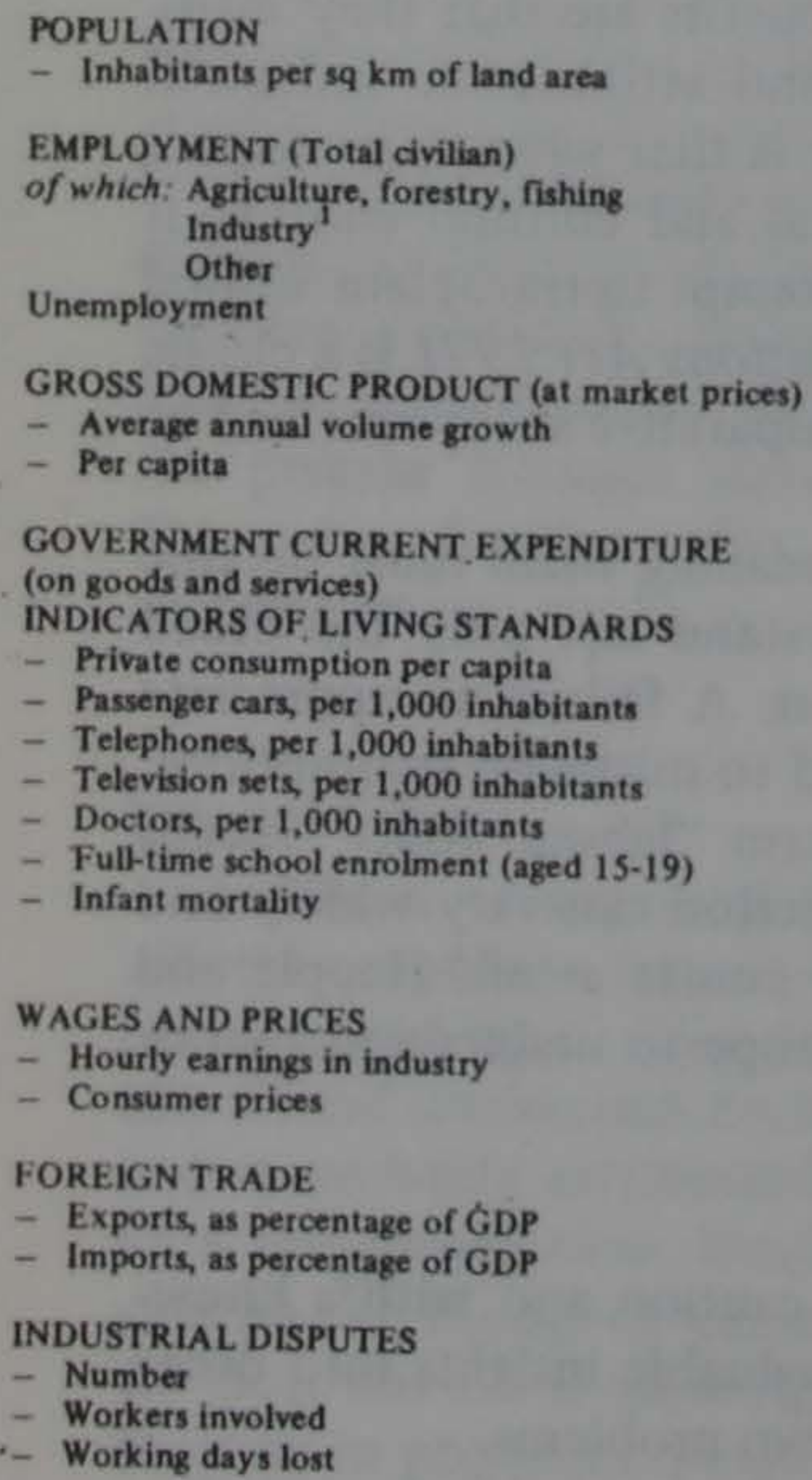

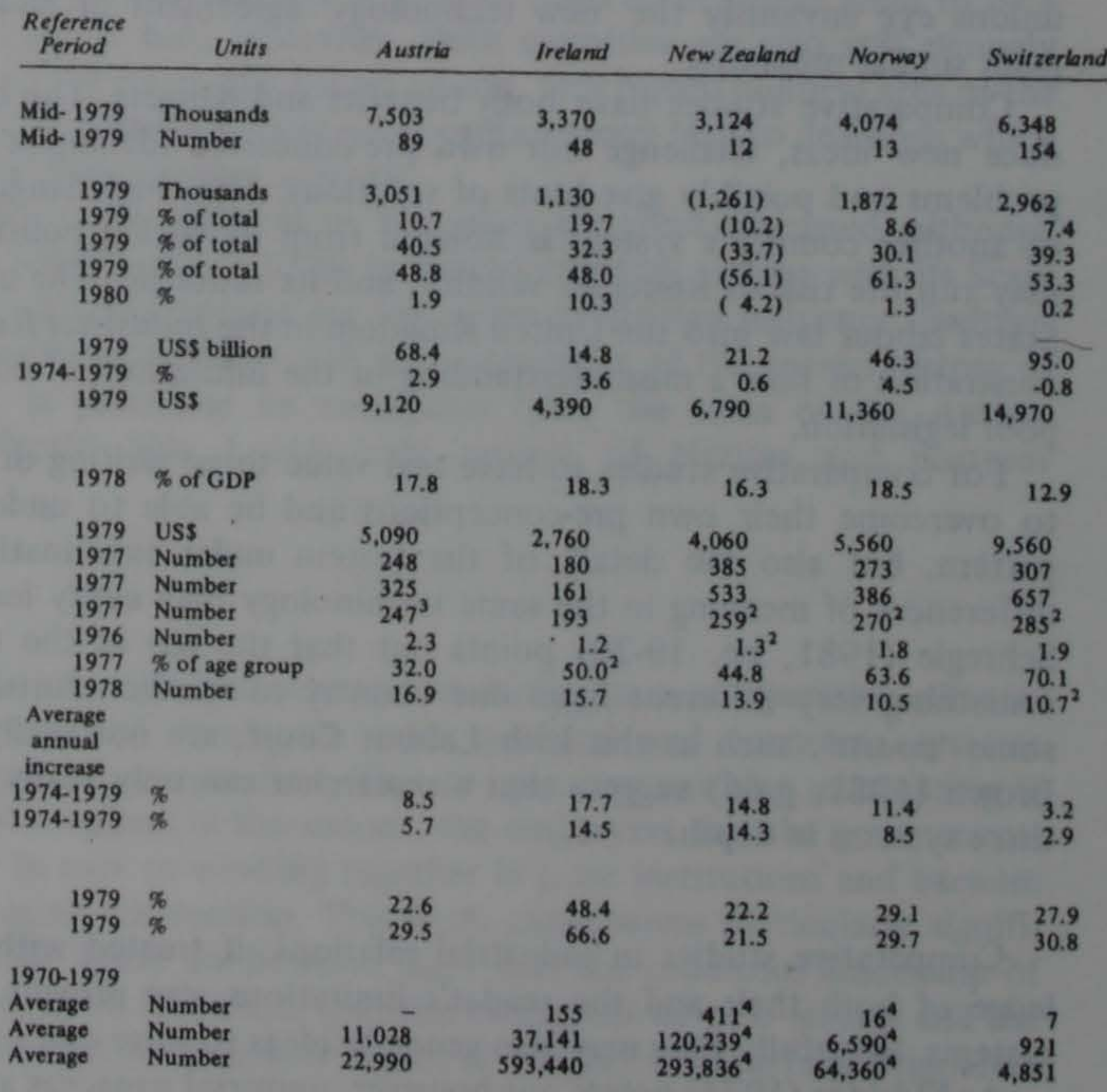

